\title{
The acquisition of a Pavlovian conditioned response in septally damaged rabbits: Role of a competing response*
}

\author{
JACK D. MASER, F. T. DIENST, and EDGAR C. O’NEAL \\ Tulane University, New Orleans, Louisiana 70118
}

\begin{abstract}
Enhanced acquisition of a classically conditioned eyelid response was found following septal injury in rabbits. Eye-opening behavior was four times more frequent in the control Ss. This suggests that faster acquisition is a function of fewer competing responses which might interfere with elaboration of the conditioned response.
\end{abstract}

Despite the large number of studies relating complex behavior to septal and/or hippocampal injury, there are few investigations where performance in response to the presentation of Pavlovian contingencies is the dependent variable. A recent study by Schmaltz and Theios (1972) reported the conditioning of the nictitating membrane in hippocampectomized rabbits. Their findings are important, because the present study is an attempt to condition rabbits suffering septal damage in a similar behavioral situation. Schmaltz and Theios observed that extensive hippocampal injury produced faster acquisition of a conditioned nictitating membrane closure than intact or cortically damaged control groups. There was also an extinction impairment in the hippocampectomized rabbits which became evident during the last 2 of 4 days of reacquisition extinction. A test for spontaneous recovery was given on the 5th day, but no significant differences between groups was found.

It may be expected that functional similarities between septally lesioned and hippocampectomized animals exist, given the intimate anatomical relationships of these limbic structures (Green, 1964; Raisman, 1966). Such similarities have appeared in the form of enhanced two-way active avoidance (King, 1958; McCleary, 1961; Isaacson, Douglas, \& Moore, 1961; Green, Beatty, \& Schwartzbaum, 1967) and as passive avoidance deficits (McCleary, 1961; Kaada, Rasmussen, \& Kveim, 1962; Isaacson, Olton, Bauer, \& Swart, 1966; Blanchard \& Fial, 1968).

On the other hand, a number of functional differences following injury to septum and hippocampus are established. For instance, Blanchard and Fial (1968) found a passive avoidance deficit correlated with crouching responses in hippocampal, but not in septal, rats. Douglas and Isaacson (1964) found that hippocampectomized rats showed a deficit in habituation to exploration of the environment, but this has not been observed in septal rats (Corman, Meyer, \&

*This research was funded by a Biomedical Sciences Support Grant. The authors gratefully acknowledge the technical assistance of Michael Downing and Stuart Dean. Reprint requests should be sent to Jack D. Maser, Department of Psychology, Tulane University, New Orleans, Louisiana 70118.
Meyer, 1967). Green, Beatty, \& Schwartzbaum (1967) also found subtle differences between septal and hippocampal rats in "warm-up" on a two-way shuttlebox, reactivity to photic stimuli, and shuttlebox intertrial activity, although, compared to control Ss, more intertrial activity occurred in both groups of lesioned animals.

McCleary (1966) hypothesized that the septal region played an important role in response inhibition, and Douglas (1967) expresses a similar role for the hippocampus. Kimble (1968) goes so far as to locate Pavlovian internal inhibition in the hippocampus. Since Schmaltz and Theios had studied the role of the hippocampus in Pavlovian conditioning, and since septum and hippocampus are theorized to be involved in inhibitory processes, we asked the question, "Does the same basic pattern as that observed by Schmaltz and Theios for hippocampectomized rabbits appear in septal rabbits?"

In contrast to the Schmaltz and Theios study, our equipment allowed us to record eye-opening responses, as well as eye closures, to the CS. The theoretical importance of this behavior is the suggestion that septal Ss perseverate a dominant response tendency because they emit fewer competing behaviors (Fried, 1972; Hamilton, 1970; McCleary, 1966; Gerbrandt, 1965). We hoped to observe directly a competing response by recording eye openings, a response which would appear to compete with eye closure and thereby interfere with conditioning. Furthermore, Siegel (1972) has suggested that eye openings to the CS reflect one or more components of the orientating reaction.

\section{METHOD}

\section{Subjects and Surgical Procedure}

Twelve male New Zealand rabbits (Oryctolagus cuniculus), obtained from local suppliers, served as Ss. They were about 6 weeks of age at the time they entered the laboratory. On the day of the operation, Ss were assigned randomly to sham-operate or septal-lesion groups. They were anesthetized with sodium pentobarbital by intraperitoneal injection. Clean surgical conditions were used for all operations.

For the septal and sham operates, the electrode was a No. 12-1/2 fine round broach (A. S. Koch \& Sons), which was 


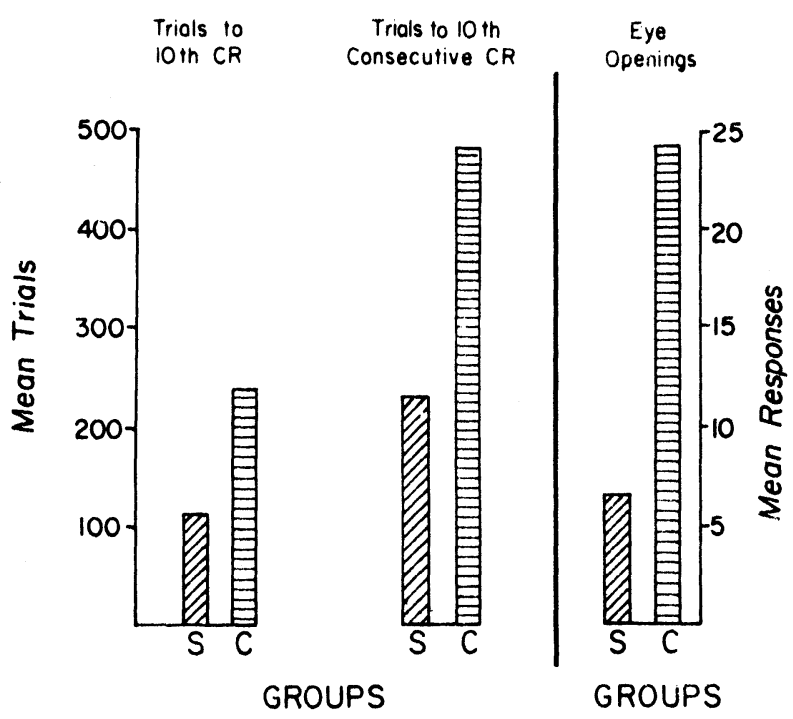

Fig. 1. On the left side: Two measures of acquisition for septal (S) and control (C) Ss. Mean trials to attain the 10th CR and to attain 10 consecutive CRs. On the right side: Mean eye-opening responses during acquisition for each group of Ss.

lowered bilaterally through holes in the skull. Depending upon the group in which the $\mathrm{S}$ was placed, the electrode was positioned either in or $2 \mathrm{~mm}$ above the septal region of each hemisphere. The broach was insulated with Insul-X, except for the tip, and served as the cathode. The circuit was completed through an anal electrode to a Grass lesion maker.

Septal animals received an $11.5-\mathrm{mV}$ current of $2.5 \mathrm{~mA}$, but the lesion maker was not activated for the sham operates. Current was passed through the electrode for $60 \mathrm{sec}$, following which the electrode was withdrawn and the skin sutured closed. All animals were injected with .1 cc Combiotic, and two stainless steel wires ( $35 \mathrm{ga})$ were inserted approximately $1 \mathrm{~cm}$ below the lower eyelid.

\section{Apparatus and Training}

During training, the Ss were kept relatively immobile in a stainless steel restraining box. Movement of the left eyelid was recorded in the following manner. A Model 85111 Conrac microtorque potentiometer mounted on a plate was taped to the S's head. Attached to the central shaft of the potentiometer was a sewing needle, through the eye of which a thread was attached. The thread was taped to the S's upper eyelid.

The potentiometer was connected to a Model BL-902 Brush recorder through a Model 721A Hewlett-Packard amplifier. The S's eyelid movements could thus be recorded by deflection of the recorder pen. A $1.5-\mathrm{mm}$ movement of the eyelid approximated a 1-mm pen deflection. The criterion for a conditioned response was arbitrarily defined as a 1-mm deflection of the pen between the onset of the CS and the US.

The conditioned stimulus was a $0.6-\sec 2,000-\mathrm{Hz}$ tone delivered at $75 \mathrm{~dB}$ through an 8 -in. speaker $2 \mathrm{ft}$ behind the $\mathrm{S}$. During acqisition, offset of the tone was immediately followed by a $75-\mathrm{mV}$ ac shock to the lower eyelid through the implanted electrodes. Shock duration was $0.2 \mathrm{sec}$. A small fan, mounted $2 \mathrm{ft}$ to the rear of the $\mathrm{S}$, provided circulating air and background noise.

On the 7 th postoperative day, training began, the procedure being the same for all Ss. Habituation to the training apparatus for $2 \mathrm{~h}$ was provided on each of the 8 th and 9 th days. Pairing of the CS and US were begun on the 10th. During acqisition, 120 trials per day were presented, with an intertrial interval varying between 30 and $90 \mathrm{sec}$. All Ss were trained to a criterion of 10 consecu tive CRs or to $70 \%$ CRs out of 120 trials.
Extinction procedures were begun the day after acquisition criterion was met. Each of the next 4 extinction days began with 20 reacquisition trials. A criterion of 10 consecutive CRs or $70 \%$ total CRs out of 20 trials was required on reacquisition prior to the onset of extinction trials. If this criterion was not met, acquisition was continued until 10 consecutive CRs were attained. This was necessary in one experimental and one control rabbit. Extinction was terminated after 10 consecutive presentations if the CS failed to produce a CR. The day following the 4 th extinction session, reacquisition trials were omitted and the CS presented alone until 10 consecu tive no-CRs were recorded. This constituted spontaneous recovery.

\section{Histology}

All Ss were sacrificed within a week of completing the above behavioral regimen. The animals were anesthetized with sodium pentobarbital and perfused intracardially with physiological saline and $10 \%$ Formalin. The brain was removed and several weeks later serially sectioned ( 40 microns) and stained with luxol fast blue.

\section{RESULTS}

Pen deflections were analyzed in five ways. The dependent measures were (1) trials to the 10th CR in acquisition; (2) trials to reach 10 acquisition CRs in a row; (3) eye openings during acquisition; (4) trials to the 10 th consecutive failure to respond in extinction; and (5) total responses in spontaneous recovery.

\section{Acquisition}

On both dependent measures of acquisition, the septally injured rabbits acquired the response more rapidly. Mean trials to the 10 th $\mathrm{CR}$ for the septal Ss was 116.17 , compared to 242.83 for sham operates $(F=$ 7.32, df $=1 / 10, p<.025)$. Observation of Fig. 1 suggests that septal animals also reach the 10th consecutive CR more quickly, and this conclusion is strengthened by a significant treatments effect $(\mathrm{F}=$ $14.67, \mathrm{df}=1 / 10, \mathrm{p}<.005)$. $\log _{1}$ o transformations were performed on the eye-opening scores for all acquisition trials. The mean number of eye openings for the septal group of 6.5 was found to be significantly less than the 23.67 mean eye openings of the sham operates $(F=$ $7.39, \mathrm{df}=1 / 10, \mathrm{p}<.025)$.

\section{Extinction and Spontaneous Recovery}

There were no reliable differences among the groups in trials to the extinction criterion $(p>.05)$. The mean number of responses during spontaneous recovery was less for the septal Ss than for the sham operates,. 15.67 and 22.5 , respectively, but this difference failed to reach significance.

\section{Histology}

Figure 2 shows brain reconstructions of the six septal Ss. The medial septal nuclei were damaged in whole or part in all Ss, and in at least three Ss all or part of the lateral nuclei were destroyed. The medial preoptic area was also damaged bilaterally in the two most extensive lesions and unilaterally infringed upon in S 2. In three other Ss, the damage was more posterior and restricted. 


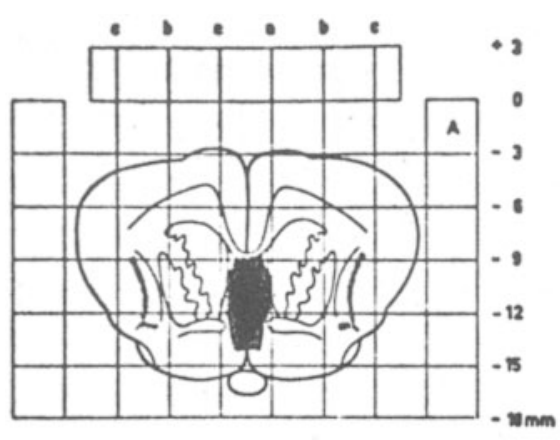

S 1

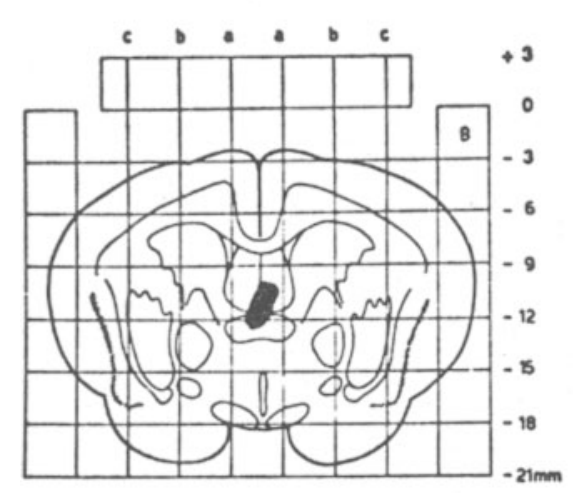

S 3
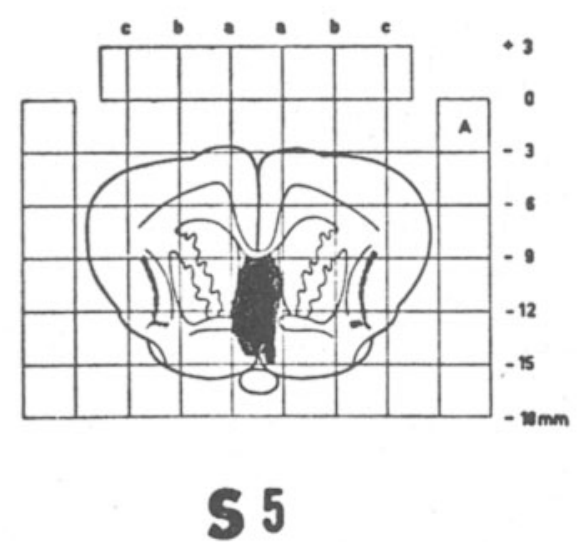

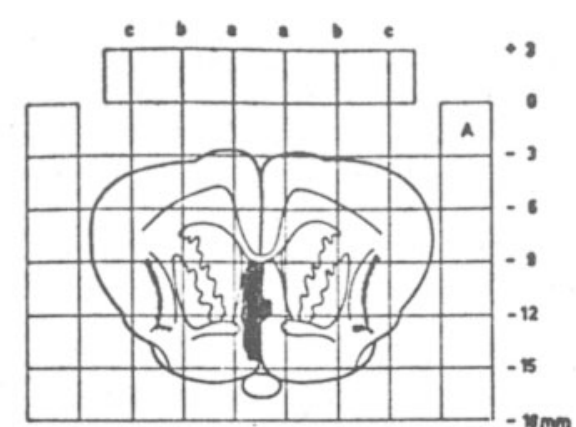

S2

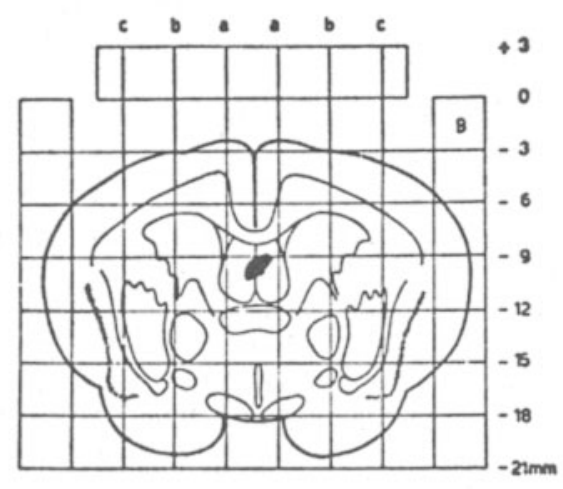

54

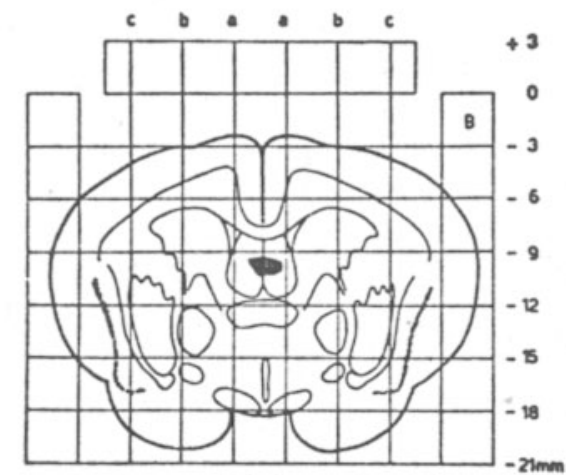

S6

Fig. 2. Histological reconstructions of the six septally damaged rabbits at the level of maximal damage. Reconstructions are from Monnier and Gangloff (1961).

Electrode track lesions to the sham operates did not enter the septal region.

\section{DISCUSSION}

In agreement with the operant literature, septally injured animals acquired the response more rapidly than did control Ss. This is consistent with Schmaltz and Theios's findings for hippocampectomized rabbits and further supports the notion of a septohippocampal functional entity.

The more important question of how this facilitation 
of learning occurs may be answered by our observation that septal damage produced fewer eye-opening responses than in control animals. Septal injury which results in response perseveration has been explained as an inability to dampen a prepotent or high-probability response. Competing or substitute behaviors are thereby prevented from emerging (Fried, 1972; Hamilton, 1970; McCleary, 1966; Gerbrandt, 1965). However, these investigators provided no direct evidence for the existence of competing activities. In the eyelid-conditioning situation, the prepotent behavior evoked early in conditioning by the CS is eye opening, not eye closure. Yet septal damage results in fewer eye openings and the prepotent response is reduced rather than perseverated.

Alternatively, Thomas, Hostetter, and Barker (1968) have considered the possibility that limbic lesions alter species-typical dispositional tendencies. To the extent that eye opening to a relatively novel stimulus represents one aspect of the rabbit's orienting response (Siegel, 1972), it might be considered a species-typical disposition. Presumably, the septal lesion reduced the probability of this dispositional tendency and thereby reduced the incidence of a behavior which might directly compete with the elaboration of the conditioned response.

The extinction data showed no significant differences between septal and control rabbits. This finding is at variance with the large litearture on septal operant behavior, as well as the Schmaltz and Theios work with hippocampectomized rabbits. Several possible reasons for the extinction findings may be suggested. It is reasonable to propose that Pavlovian extinction mechanisms are different from those involved in operant extinction. For instance, the frustration and crossover effects are seen only in operant situations, and whereas extinction of a CR appears very much an associative phenomenon, extinction of an operant appears to involve motivational and emotional overtones. It is also possible that septal and hippocampal extinction processes are different, but this conclusion requires further research. A final suggestion is that eye opening plays no role in extinction and should not affect extinction of the CR as it affected acquisition. If this outcome could have been foreseen, no differences between groups would have been predicted during extinction.

Although the negative data on spontaneous recovery are in agreement with that of Schmaltz and Theios's hippocampectomized rabbits, it would be difficult to conceive otherwise in the absence of an extinction effect.

A number of procedural differences between the Schmaltz and Theios study and the present one must be taken into account. Possibly, the use of a .25 -sec interstimulus interval in the hippocampal study and our use of $.6 \mathrm{sec}$ is the most important difference. Frey
(1969) has shown that interstimulus intervals of $.4 \mathrm{sec}$ produce better acquisition than do those of $.6 \mathrm{sec}$, and performance improves further down to $.2 \mathrm{sec}$ (Frey \& Ross, 1969). Another important change in the present study was to measure the eyelid response rather than the nictitating membrane. Both of these modifications probably contributed to the relatively large number of trials required by our Ss to acquire the response.

\section{REFERENCES}

Blanchard, R. J., \& Fial, R. Effects of limbic lesions on passive avoidance and reactivity to shock. Journal of Comparative \& Physiological Psychology, 1968, 66, 606-612.

Corman, C. D., Meyer, P. M., \& Meyer, D. R. Open-field activity and exploration in rats with septal and amygdaloid lesions. Brain Research, 1967, 5, 469-476.

Douglas, R. J. The hippocampus and behavior. Psychological Bulletin, 1967, 67, 416-442.

Douglas, R. J., \& Isaacson, R. L. Hippocampal lesions and activity. Psychonomic Science, 1964, 1, 187-188.

Frey, P. W. Differential rabbit eyelid conditioning as a function of age, interstimulus interval and cue similarity. Journal of Experim ental Psy chology, 1969, 81, 326-333.

Frey, P. W., \& Ross, L. E. Rabbit eyelid conditioning: Effects of age, interstimulus interval and intertrial interval. Developmental Psychology, 1969, 1, 276-279.

Fried, P. A. The septum and behavior: A review. Psychological Bulletin, 1972, 78, 292-310.

Gerbrandt, L. Neural systems of response release and control. Psychological Bulletin, 1965, 64, 113-123.

Green, J. D. The hippocampus. Physiological Review, 1964, 44, 561-608

Green, R. H., Beatty, W. W., \& Schwartzbaum, J. S. Comparative effects of septo-hippocampal and caudate lesions on avoidance behavior in rats. Journal of Comparative \& Physiological Psychology, 1967, 64, 444-452.

Hamilton, L. W. Behavioral effects of unilateral and bilateral septal lesions in rats. Physiology \& Behavior, 1970, 5, 855-859.

Isaacson, R. L., Olton, D. S., Bauer, B., \& Swart, P. The effect of the number of training trials on the deficit in passive avoidance behavior in the hippocampectomized rat. Paper read at Midwestern Psychological Association, Chicago, 1966.

Kaada, B. R., Rasmussen, E. W., \& Kveim, O. Impaired acquisition "of passive avoidance behavior by subcallosal, septal, hypothalamic, and insular lesions in rats. Journal of Comparative \& Physiological Psychology, 1962, 55, 661-670.

Kimble, D. P. Hippocampus and internal inhibition. Psychological Bulletin, 1968, 70, 285-295.

King, F. A. Effects of septal and amygdaloid lesions on emotional behavior in the rat. Journal of Nervous \& Mental Disease, 1958, 126, 57-63.

McCleary, R. A. Response specificity in the behavioral effects of limbic system lesions in the cat. Journal of Comparative \& Physiological Psychology, 1961,54,605-613.

McCleary, R. A. Response-modulating functions of the limbic system: Initiation and suppression. In $E$. Stellar and J. M. Sprague (Eds.), Progress in physiological psychology. Vol. 1 . New York: Academic Press, 1966.

Monnier, M., \& Gangloff, H. Rabbit brain research. Vol. I. Atlas for stereotax ic brain research. Amsterdam: Elsevier, 1961.

Raisman, G. The connexions of the septum. Brain, 1966, 89, 317-348.

Schmaltz, L. W., \& Theios, J. Acquisition and extinction of a classically conditioned response in hippocampectomized rabbits (Oryctolagus cuniculus). Journal of Comparative \& Physiological Psychology, 1972, 79, 238-333.

Siegel, S. Latent inhibition and eyelid conditioning. In A. H. Black and W. F. Prokasy (Eds.), Classical conditioning II: Current theory and research. New York: Appleton-Century-Crofts, 1972.

Thomas, G. J., Hostetter, G., \& Barker, D. J. Behavioral functions of the limbic system. In E. Stellar and J. M. Sprague (Eds.), Progress in physiological psychology. Vol. 2. New York: Academic Press, 1968. Pp. 229-311.

(Received for publication November 20, 19.73; revision received February 7,1974 .) 